\title{
泡沫混凝土技术在公路路基填筑中的应用研究 --以句容河大桥引桥路基为例
}

任翠华

江苏苏科建设项目管理有限公司，江苏 南京 210000

[摘要] 随着时代的进步和社会经济的发展，我国交通量越来越大，过去修建的公路采用的灰土或是碎石土已经无法满足目高 填方路基施工的要求。泡沫混凝土可提高工程施工质量, 降低作业难度, 提高作业人员的安全性, 加快工程进度, 通过对混 凝土配合比、施工工艺、施工通病与防治等开展叙述分析, 并与其它填料进行经济技术和社会环境效益对比, 认为泡沫混凝 土技术非常适合公路高填方路基填筑施工。

[关键词]泡沫混凝土; 公路路基高填方; 填筑; 沉降; 防治

DOI：10.33142/ec.v2i6.426 中图分类号：U416.1 文献标识码：A

\section{Study on the Application of Foam Concrete Technology in Highway Subgrade Filling-Taking the Subgrade of the Approach Bridge of Gulong River Bridge as an Example}

REN Cuihua

Jiangsu Science Construction Project Management Co., Ltd., Jiangsu Nanjing, 210000 China

\begin{abstract}
With the progress of the times and the development of the social economy, the traffic volume of our country is becoming more and more large. The foam concrete can improve the construction quality, reduce the operation difficulty, improve the safety of the working personnel, and accelerate the progress of the project. The concrete mix ratio, the construction process, the common quality problems and the prevention and control of the concrete can be analyzed and analyzed, And compared with other fillers for economic and social environmental benefit, the foam concrete technology is considered to be very suitable for the filling construction of the high-filling subgrade in the highway.
\end{abstract}

Keywords: Foam concrete; Highway subgrade high filling; Settlement; Prevention and control

\section{引言}

泡沫混凝土是混合一定比例的泡沫和水泥泥浆的一种新型建筑填充材料, 泡沫和水泥泥浆的混合物通过浇筑固化 后, 凝固的混凝土内含有大量的均匀的封闭气孔。通过泡沫混凝土稳定的结构、较轻的凝固密度质量、制作施工也很 方便安全等多个良好的特点, 使其在公铁项目和建筑行业得到了非常普遍的应用。

1 泡沫混凝土强度形成原理、技术特性及其优势

1. 1 泡沫混凝土的的形成原理

泡沫混凝土内包含许多不同尺寸的气孔和孔壁，泡沫在水泥泥浆里面产生了气孔，材料的颗粒和反应物还有气孔 的间隙孔形成孔壁, 这些成分共同组成了泡沫混凝土。其中组合物的成分不同, 混合物的性能不同直接决定了混合产 生的泡沫混凝土的不同性质, 凝胶材料在泡沫混凝土中的使用, 产生了混凝土的主要强度。虽然泡沫混凝土中含有大 量的气泡, 这些气泡在传统的观念中往往意味着混凝土的强度不足, 但是这种泡沫混凝土的强度依然可以满足一些建 筑的使用标准。

\section{2 泡沫混凝土技术特性}

首先是密度低, 泡沫混凝土的密度大约为 $520 \mathrm{~kg} / \mathrm{m}^{3}-560 \mathrm{~kg} / \mathrm{m}^{3}$, 而传统的灰土密度约为 $1780 \mathrm{~kg} / \mathrm{m}^{3}$; 碎石土密度更 大。泡沫混凝土在混凝土中存在这很多独立的封闭胶体气泡, 这些气泡并非传统意义上的空隙, 气泡膜的韧性很高, 由于封闭性强, 气泡间是不融通的, 因此材料的强度更大。泡沫混凝土的另一个特性是可以通过水泥泥浆的选择, 不 同混合材料的添加以及气泡含量的控制来有效的调节泡沫混凝土的强度 ${ }^{[1]}$ 。还有就是泡沫混凝土的流值很高, 通过计算 泡沫混凝土的流值在 160 毫米到 180 毫米之间, 因此可以采用管道洜送的方法来运输泡沫混凝土, 也可以进行远距离 的输送。

\section{3 泡沫混凝土在高填方路基中的优势}

泡沫混凝土在凝固之后, 由于里面含有大量的气泡, 具有很强的隔音、抗冲击、防水防火、和保温隔热以及使用 寿命长等特点, 由于其低密度, 故整个泡沫混凝土的自重较传统的灰土或碎石土, 轻很多, 这样可以降低路基的自然 沉降, 有利于降低桥头跳车现象。其次泡沫混凝土所用原材料, 只有水泥和泡沫剂, 水泥现场一般采用散装水泥, 水 
泥运至现场, 导入水泥罐中, 封闭式施工, 减少扬尘, 环保性能好。传统的灰土和碎石土施工, 不可避免的会引起大 量扬尘, 环保效应差, 给周围群众生产和生活带来不利影响。社会环境效应差。而泡沫混凝土施工, 能避免这些不利 环境影响, 故在城市周边和离原材料较远的地区施工得到推广。最后, 由于泡沫混凝土大量气泡存在, 故其隔音效果 以及抗冻融性都比较的好。

\section{2 工程概述}

句容河大桥引桥路基段根据《公路工程技术标准》(JTGB01-2014), 将硬路肩宽度由 2.5 米调整为 3 米, 公路断面总 宽度相应的调整为 34 米, K47+260.000K49+400. 000 路基全宽 33 米, 断面构成包含了 0.75 米的土路肩和 0.25 米的硬路 肩, 还有 3 条 3.75 米的行车道以及 0.50 米的左侧路缘带和 3 米宽的的中央分隔带, 0.5 米的左侧路缘带, 3 条 3.75 米的行车道, 2.5 米的硬路肩, 0.75 米的土路肩。行车道、硬路肩路拱横坡采用 $2 \%$, 土路肩路拱横坡 $4 \% K 47+450.000 \sim K 48+750.000$ (新建段) 路基全宽 34 米, 断面构成包含了 0.75 米土路肩, 3 米硬路肩 (含 0.5 米右侧路缘 带), 3 条 3.75 米的行车道和 0.5 米的左侧路缘带以及 3.0 米的中央分隔带, 0.5 米的左侧路缘带和 3 条 3.75 米的行 车道, 3 米的硬路肩 (含 0.5 米的右侧路缘带) 以及 0.75 米的土路肩。其中 K48+750.000 K49+100 需进行平面线位改造 及纵面的局部抬高顺接桥. 该工程的施工建单位和项目建造的委托方, 项目建造设计方, 项目监理方等相关部门和建造 工程师以其对项目现场进行了详细的、多角度的实地勘查, 并研究讨论租后制定了具体的路基项目施工建造方案, 主 要就是在路基两侧设置抗滑桩, 抗滑桩的中间浇注填充泡沫混凝土。通过泡沫混凝土的优越特性减少路基回填的荷载, 同时尽可能的消减路基沉降差。

\section{3 施工方案之比选}

(1) 传统石料回填。由于石料回填需要一个晾晒处理, 从而把石料的含水量控制在一个合理的范围内, 但是在 6 月至 8 月南京处于一个长时间的梅雨季节, 受到连续降雨的影响, 这个时间段内无法完成石料的晾晒, 而且回填施工 难度也因为降雨而加大。最主要的是该项目的周边没有足够的可供回填的石料。其次, 石料的填充需要压路机进行碾 压，而此损坏的路段比较狭窄，压路机是难以进场进行碾压操作的，回填的质量无法达到相关标准。

（2）原路基料换填方案。如果在建筑施工的工地附近没有直接可供回填的石材，可以使用原来填充路面土石材料 进行处理后的回填, 但是还是受到梅雨季节的影响, 这个时间段内无法完成石料的晾晒, 石料含水量没办法实现控制, 同时晾晒场地需求较高难以满足, 而且原路基料的换填也需要重型碾压机进行碾压, 但是在这个狭窄损坏的路段压路 机是难以进场进行碾压操作的，回填的质量无法达到相关标准，回填施工难度也因为降雨而加大，

（3）泡沫混凝土换填方案。由于泡沫混凝土具备的一些特性，可知泡沫混凝土在路基填充的时候不需要压路机进 行碾压, 也无需进行振捣。因为其良好的流动性可通过管道进行输送, 并在狭小的空间内完成路基的施工, 基本不受 天气影响, 施工工艺简单, 社会环境效益好, 无扬尘、无污染, 受气候条件影响小, 更主要的是换填完成一周以后就 可以再进行后续的路面施工了。

(4) 最后的路基施工建造计划已经完成论证。通过与传统土石材料回填以及原路基料换填等方式进行了多角度的 比较, 泡沫混凝土以其较高的强度和便捷的施工方式非常满足该路段施工设计的要求, 此外, 应用该材料的新路基和 旧有路基的沉降差可以尽可能的减小。在充分的考量该项目面临的梅雨季节气候影响、项目附近无回填石料、项目的 工程实际使得一些重型设备无法进场等等因素之后, 经过仔细审查和充分的论证后, 决定渝蓉高速公路 K $15+900$ 段的 水毁路基用泡沫混凝土这种材料来进行换填 ${ }^{[2]}$ 。

\section{4 泡沫混凝土施工工艺}

（1）设计水毁路基的换填方案：为了确保该高速公路段路基的总体稳定，在以泡沫混凝土的方式进行换填后，仔 细养护一周左右, 再进行后续施工恢复原始路面以及路面上的辅助设备。

（2）原本的路基挖除工作和路基初步处理：根据施工建造的设计方案，分 4 米到 8 米的台阶，进行原本浸水路基 的挖出工作。该泡沫混凝土基底采用碎石垫层, 浇筑前要检查, 保证基底无杂物、无积水; 基底高程、平面尺寸满足 设计施工的整体要求。

(3) 泡沫混凝土的制作和施工:

(1)制作

水泥砂浆、发泡剂以及压缩空气进行充分的混合, 形成泡沫混凝土。分两个步骤进行生产。首先要由发泡剂进行 水溶, 在和压缩空气用发泡的设备进行充分的混合。然后将水泥砂浆和第一步的发泡产物按照项目要求的混合比例, 用轻质泡沫土制备站进行 5 分钟左右的搅拌, 直到搅拌的泡沫混凝土的流度在 210 毫米左右的时候, 即可通过管道输 送到换填施工区域。这个时候, 制作完成的泡沫混凝土的水灰比为 0.7 , 湿密度大概是 550 公斤每立方米, 气泡率整体 上在 $68 \%$ 上下。 
(2)施工

浇筑区域的划分必须以建筑工地的具体情况和现场实际为基础。在 0.3 米至 1.0 米范围内, 控制泡沫轻质土的单 层浇筑厚度, 并建议控制在 0.4 米范围内进行。同时按照泡沫混凝土的制作设备的生产力来决定单块的浇筑区域的大 小, 因为泡沫混凝土具有良好的流动性, 在浇筑过程中无需振捣只要用铝合金刮杜把表面涂抹平滑就可以了, 当泡沫 混凝土的表面凝固以后, 在上层盖上土工布进行至少为期一周的养护 ${ }^{[3]}$ 。

（4）路基完成后养护和工程验收。浇筑完成的 3 天内严格禁止任何人在泡沫混凝土浇筑表面上走动。同时在为期 一到两周的养护期期间不允许在混凝土表面堆积重物, 以免损害内部的气泡。对细胞混凝土的取样是主要检查样本的 强度、流动值以及湿密度和内部气泡的密度。7 天强度和 28 天强度均需要检测。经检验合格后方可进行下道工序施工 (路面铺筑)。

\section{5 泡沫混凝土技术在公路路基填筑工程中的应用要点}

在泡沫混凝土的制造过程中，必须充分混合水泥和水，加入发泡装置压缩空气而产生的泡沫，均匀混合泥浆和气 泡, 并注意减少混合搅拌的强度, 如果气泡超量, 那么这份泡沫混凝土就可以作废处理了。泡沫混凝土可以使用㫤管 来进行远距离的输送, 浇铸管的长度必须要设置充足, 由于流动性良好, 泡沫混凝土的最大管道输送距离可达到约 500 米。如果浇注口位于浇注区之外, 出口有泡沫混凝土出现时, 浇注管需要转移到浇注区, 泡沫混凝土沿着模板的边缘 进行浇注, 如果浇铸高度过高, 则更需要边缘浇注的步骤。如果在浇注工艺中使用多个浇注管道, 那么在浇注的时候 我们可以同时从一端开始并排进行浇注; 如果浇注的高度过高, 可以从中间浇注到周围区域。在浇注之前, 必须将浇 注的管道插入泡沫混凝土中, 必须确保浇注的管道出口相对于泡沫混凝土是水平的, 在平扫泡沫混凝土表面的时候, 也必须保持浇注口的水平。

泡沫混凝土的浇筑前要用强度足够的预制钢模板进行支立, 同时必须对支立的模板进行施工前核验, 以确保基板 没有积水, 而且其排列紧密缝隙不大。在暴雨天气的情况下, 浇灌泡沫混凝土的施工是没办法进行下去的。这个项目 的模板支力使用的就是钢模, 在泡沫混凝土浇注施工的过程中, 由于泡沫混凝土中的一些气泡破裂致使体积压缩, 重 量维持不变的情况下混凝土的湿密度就会随着气泡的消泡而增大, 因此, 通常情况下会使用 $30 \mathrm{CM}-\mathrm{B}$ - 0 CM 的浇注厚度 标准, 同时把台阶放在顶层并使之固定。在泡沫混凝土的基底层上放置厚度为 3CM 的砂石层, 两层 25 平方厘米的正方 形钢丝片放置在距离上下层皆为 $50 \mathrm{~cm}$ 的位置上, 其中钢丝片的规格为直径 $3 \mathrm{~mm}$ 的钢丝, 以 $10 \mathrm{~cm}$ 长度来控制网片的搭 接。在冬季的泡沫混凝土浇注的时候, 必须要维持浇注温度高于冰点, 在泡沫混凝土的固化和养护的阶段, 必须在上 面覆盖保温材料, 以防止低温对于混凝土凝固的影响。

\section{6 效益分析}

句容河大桥引桥的路基是用泡沫混凝土的换填方式来建造的，和传统的一些换填方式相比，泡沫混凝土换填排除 了项目周边石料来源供应、雨雪低温等自然天气的不利影响、施工现场场地客观条件的限制和路基填料质量保证等问 题, 同时由于泡沫混凝土在制作、浇注、养护方面的简便，大大缩短了路基施工时间，确保尽早的、按工期保质保量 的完成 K $15+900$ 段公路的建设, 保证了该条路线的运行通常, 确保交通按时恢复, 为沿线的人民带去可靠的交通保障。

\section{7 结语}

泡沫混凝土具有的湿密度小、施工工艺简单、低弹减震性能优越、防水防火、承压强度大、综合性能优良等多个 特点, 使其具有满足公路路基施工建设的设计标准要求，同时它的养护时间短，可以快速的完成紧急情况下的路基维 护工作, 从而确保道路的及时、安全、可靠和良好运行。除此之外, 泡沫混凝土还具有良好的环境保护和资源友好的 特点, 在施工过程中不产生有害物质, 没有灰尘和其他产物, 并且可以在一些特殊的气象环境下完成浇注工作, 在一 些老旧的破损道路维修和特殊环境下需要快速维修的道路等条件限制下，泡沫混凝土具备广阔的应用和发展空间。

\section{[参考文献]}

[1] 吴颖峰。泡沫混凝土技术在公路路基填筑中的应用研究 [J]. 浙江交通职业技术学院学报, 2018 (5) : 56-57.

[2]石䓏.泡沫混凝土在公路路基塌方事故处理中的应用技术 [J]. 黑龙江科学, 2014(1) : 45-46.

[3] 张少山.轻质泡沫混凝土在桥梁台背回填中的应用研究 [J].中国科技投资, 2017 (7) : 63-64.

作者简介：任翠华（1984-)，毕业学校：江苏大学；现就职于江苏苏科建设项目管理有限公司总监。 